\title{
Promoting a Central Learning Management System by Encouraging Its Use for Other Purposes Than Teaching
}

\author{
Franz Reichl and Andreas Hruska \\ E-Learning Centre, Vienna University of Technology, Gusshausstr. 28/E015, \\ A-1040 Wien, Austria \\ \{Franz.Reichl, Andreas.Hruska\}@elearning.tuwien.ac.at
}

\begin{abstract}
Vienna University of Technology's E-Learning Centre introduced Moodle in 2006 as the university's central learning management system. Custom interfaces to existing IT infrastructure as well as modules developed and deployed according to user's needs provide for a seamless digital workflow in the university's teaching, learning and organisational processes. Encouraging the use of the LMS as a multi-purpose tool to support all kinds of co-operation and communication activities in addition to curricular teaching led to a rapid and significant increase in user numbers and encouraged university teachers to deal with educational questions and to develop innovative learning and teaching solutions, based on the LMS.
\end{abstract}

Keywords: e-learning, learning management systems, Moodle, learning communities, communities of practice, collaborative work, business integration.

\section{Background}

Vienna University of Technology's administrative software TUWIS has grown over more than 40 years; modules to satisfy urgent needs and demands have been added step-by-step, resulting in a very heterogeneous and expensive to maintain enterprise information technology landscape with complex interfaces.

Concerning e-learning, the situation was similar until a few years ago. Entrepreneurial teachers and researchers at Vienna University of Technology had carried out many successful projects and activities beyond self study which were able to demonstrate that immense benefits can be achieved by media supported learning, e.g.:

- iChemEdu $[1,2]$ developed an internet-based laboratory information and management system, iChemLab, an e-book based e-content pool, iChemLecture, and an e-self-assessment tool, iChemExam; an ever growing database application initially containing more than 450 detailed synthetic experimental protocols has been developed by extracting and revising information from some 8,600 student work reports collected over the last years;

- MODULOR and virtual campus for architecture [3]: to support face-to-face learning, the faculty for architecture started to implement a virtual campus, consisting of a learning portal, a media database, and groupware and courseware tools;

- blended learning in continuing education, with active facilitation [4]. 
Many of the successful and sustaining projects have developed their own hardware and software solutions. While some of these systems contain interfaces to the university's administration system, many of them were implemented as stand-alone solutions with their own registration and authentication modules - thus resulting in redundant and partly inconsistent data.

\subsection{Evolving E-Learning and E-Teaching Strategies}

In 2004, a new University Law released the Austrian universities into autonomy and gave them the opportunity and the obligation to develop their own strategies. Vienna University of Technology founded an E-Learning Centre as an organisational and administrative structure to consolidate earlier e-learning and e-teaching initiatives and to make the experiences and developments sustainable and applicable for a wider group of users. The E-Learning Centre supports teachers and students in all departments and all fields of study and maintains and permanently improves e-education tools.

The university's strategy aims at improving the quality and efficiency of their study offers: the application of new media shall intensify learning processes, improve learner's perception of complex subjects, and it shall enable particular groups of students to participate in courses who would otherwise be disadvantaged. The university's medium to long term goal is to support each basic course in initial studies by means of e-learning - not by replacing the face-to-face courses, but by establishing blended learning as the standard in learning and teaching. In parallel, learning provisions are improved with respect to quality management. Establishing quality standards follows state of the art processes as defined by ISO 9000 and ISO 9126 and described by various publications, e.g. [5].

According to Hagner's characterisation of technology adaptors (distinguishing between entrepreneurs, second wave, reward seekers, and reluctants [6]), Vienna University of Technology aimed at creating a large group of second wave adopters by consolidating entrepreneurs' initiatives and by building a "learning community of practice" among the university's teaching professionals. To take the reward seekers on board, the rectorate has initiated an annual E-Learning Award for outstanding achievements in teaching with new media, encouraging teachers to share their achievements with colleagues.

To create synergies, three significantly different universities in Vienna (University of Technology, University of Natural Resources and Applied Life Sciences, Academy of Fine Arts) collectively developed, implemented and evaluated their e-learning and e-teaching strategies; they joined forces in the project Delta $3[7,8,9,10,11]$ which was carried out from October 2005 to September 2007 and was co-funded by the Austrian Federal Ministry for Education, Science and Culture during the tendering for e-teaching/e-education strategies at universities and Fachhochschulen [12].

\subsection{Implementing E-Learning Services and Infrastructure}

A successful blended learning strategy requires comprehensive offers for support, consultation, and qualification of university teachers, students and managers. Since the university followed a holistic approach for implementing e-learning strategies, 
dealing with strategic, organisational, administrative, financial, and legal aspects, didactics and curricular integration, competence and expertise, acceptance and incentives, public relations and marketing, and quality assurance (compare [13]), efficient and effective implementation of such a strategy requires to develop users' competencies in many such areas. Thus, the E-Learning Centre developed a portfolio of information and qualification offers that can be rapidly adapted to different needs and demands of users at the university. Integrated support structures have been created which offer a wide spectrum of individualised, problem oriented (or rather solution oriented), low threshold services to university teachers, adequate for any need and any amount of time available, ranging from online FAQs and a helpdesk to consultancy, information events and workshops, as well as coaching and guidance [11].

\section{Implementation and Application of Moodle as the Central LMS}

The use of a centrally managed and maintained learning platform significantly increases the efficiency for teachers and students, leads to a more homogeneous presentation of learning provisions, and reduces management and support overhead.

The E-Learning Centre of Vienna University of Technology implemented the LMS (Learning Management System) Moodle (Modular Object-Oriented Dynamic Learning Environment) as its central LMS under the university specific "brand name" TUWEL (Technische Universität Wien E-Learning) with specific adaptations towards the university's corporate design, with interfaces to existing services, and with features and functions in order to support specific teaching and learning processes. Moodle is open source software with currently more than 28 million users on approximately 50,000 registered validated sites in more than 200 countries [14].

The most important extensions to Moodle were features allowing the integration of the LMS TUWEL into the university's existing administration systems, thus enabling the use of existing data without having to duplicate them. Access to TUWEL is controlled via the university's centrally managed authentication system so that all staff members and students can use the learning platform immediately, without additional administrative entry barriers. Information provided by TUWIS upon login is used by TUWEL to determine authorisation and rights of users, so that teachers have access to all the courses provided by their department. Upon every login, user data in TUWEL are updated from data in the central administration system. Additional interfaces connect the already existing e-learning tools (e.g. iChemLab, iRecord) to TUWEL and thus also to the administration system.

Data concerning authentication, authorisation, enrolment, group management and meta-data on lectures are imported into TUWEL, and grades can be calculated from results of learning processes and exported from TUWEL back into the administration system TUWIS. All these features are implemented in a Moodle block "TUWEL Toolbox" so that they can be accessed easily from within each TUWEL course $[15,16]$. On the other side, TUWIS (which contains all the relevant information) has been enhanced with a menu entry to generate and to announce a course in TUWEL, based on available data from TUWIS; this feature also automatically generates links between course entries in TUWEL and in TUWIS [15, 17]. 


\subsection{Specific Features}

The standard open-source software package Moodle has been enhanced with special features oriented at educational requirements and based on users' needs and requirements to support faculty specific learning processes, e.g.:

- "checkmark assignments": in many courses, students have to solve exercises at home and have to declare (by entering checkmarks into a list of exercises) before the start of a face-to-face group meeting which exercises they were able to solve; during the meeting, randomly selected students have to demonstrate their solutions; the process of submitting the "checkmarks" and the grading of the assignment are represented in TUWEL's assignment type "checkmark assignment";

- advanced "working group" handling: for splitting large numbers of learners into groups, student working groups can be built in TUWEL in addition to the groups defined in TUWIS; teachers define the number of groups and the maximum number of participants per group; students can then form groups with their colleagues, and a learning product jointly developed for an assignment can be uploaded by one of the students; teachers are able to grade such an assignment for the whole group;

- "activity reports": this feature provides teachers with the possibility to anonymously contact groups of students depending on their activity (or non-activity) level with regard to specific assignments or downloads of documents;

- advanced display features, e.g.: mathematical notation, rendering of LaTeX notation, molecular rendering of Jmol descriptions as 3D visualisations, syntactic highlighting of programming language code, displaying mind-maps created with the open-source software freemind via a flash plug-in $[15,18]$;

- advanced scheduling: a powerful scheduler enables teachers to announce a number of time slots to their students, e.g. for oral examinations, for discussing the results of their exercises, or for meetings during office hours; several teachers and tutors of a course may generate time slots, and students are able to see all time slots provided by all relevant teachers and to register for a specific time;

- iRecord: a media-based e-portfolio has been developed by the faculty for architecture; a specific TUWEL assignment feature allows the submission of documents from TUWEL assignments directly into the iRecord system [15].

\subsection{Promoting the LMS for E-Learning, E-Teaching - and beyond}

A low threshold usage of the centrally maintained learning platform was solicited, aiming at first increasing the quantity of e-learning provisions; later on, every course shall use the centrally supported learning management system and apply those of its functions (administration, content-presentation, organisation of learning activities, communication, feedback, assessment) which are relevant for the specific course. We correctly expected that awareness for the quality of (online) learning and teaching would rise at a later stage, after teachers took their first attempts; like other universities, we experienced that the application of an LMS and the availability of support and training have encouraged the university teachers to deal with educational questions and to develop innovative solutions, thus influencing teaching in a positive way [11]. 


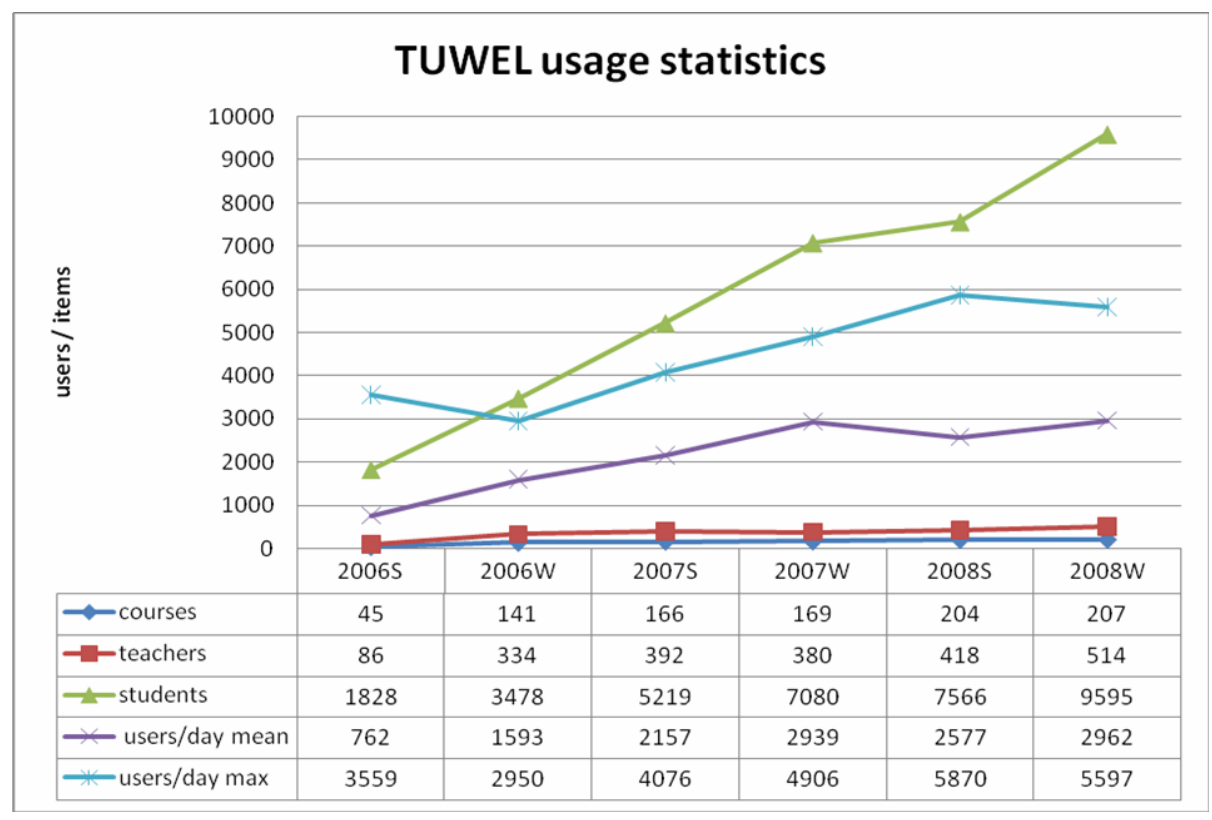

Fig. 1. TUWEL LMS use by semester (number of teachers includes staff and tutors)

TUWEL went online in March 2006 with less than 50 courses created by teachers of the computer science faculty. The big challenge was - and still is - to promote the benefits of deploying the platform for teaching purposes. In October 2008, TUWEL provides approximately 350 different courses per year (see Fig. 1). The platform is used almost any time and by up to 5,870 different users per day (see Fig. 2).

Like at many other universities, the centrally supplied LMS is used by approximately $15 \%$ of the teachers. However, many learning activities applying new media have evolved in parallel (e.g. [19, 20]). As expected, the platform was most intensively used by the faculties and departments with the largest number of students (Informatics: 5.277 students, 874 beginners in winter term 2008/09; Architecture: 3,968 students, 842 beginners in winter term 2008/09 [21]). The largest "regular" courses for students, with up to 800 participants, are - as expected - from these two faculties.

However, the LMS TUWEL is not only used for courses in regular curricula but also for courses for the university's staff members, e.g.:

- a welcome-event "getTUgether" is offered twice per year and provides new staff members with information about the university's structure and organisation, services and service units;

- specific information and training is offered for security officers and fire wardens;

- the university's library offers introductory courses to students and researchers;

- introduction to the LMS's features is also provided in TUWEL in several formats (e.g. content creation tutorials, TUWEL tutorials). 


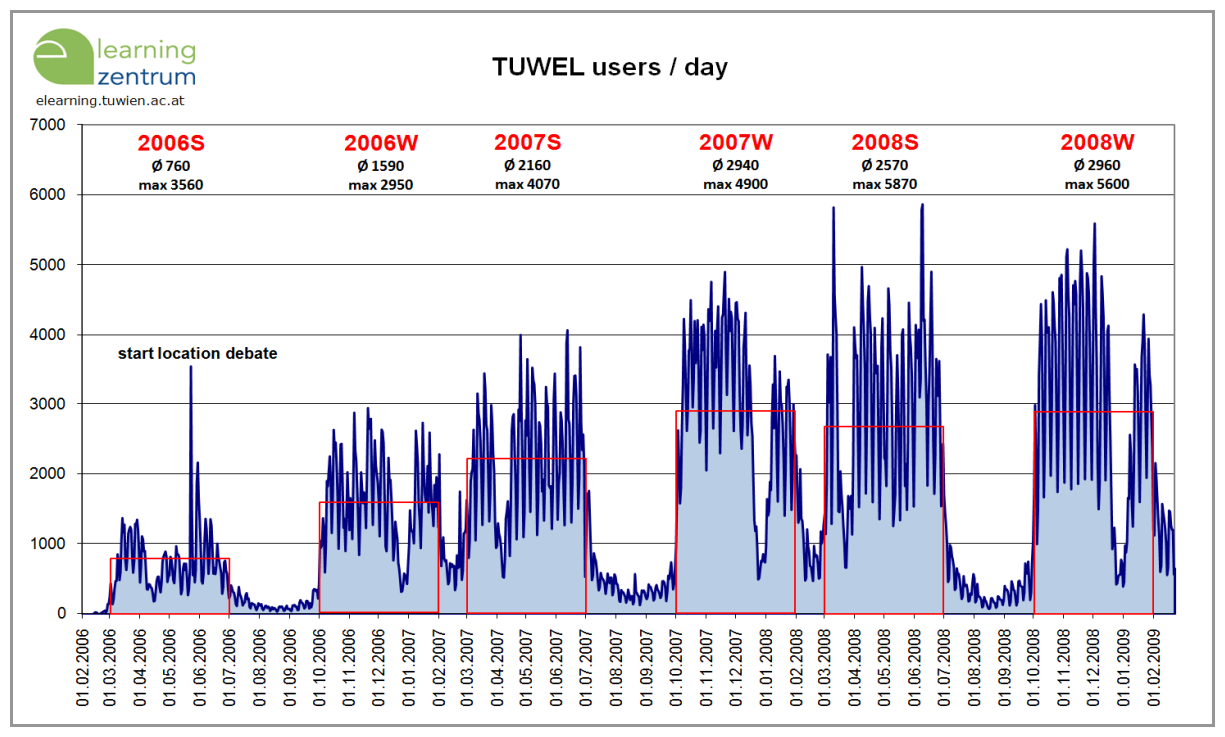

Fig. 2. Increase in the number of different TUWEL users per day

Interestingly enough, the university's management and the central university offices and service departments very soon discovered the capabilities and benefits of such a platform which is easily available and accessible to all university employees and students. They thus use the TUWEL platform regularly for communication, co-operation and administrative purposes, e.g.:

- the E-Learning Centre itself uses TUWEL to administer the annual E-Learning Award: general information is provided in "online resources", the upload of applications is handled by TUWEL's assignment feature which allows the jury members to download and evaluate the applications;

- in the year 2006, the university had to decide whether to build a new campus at the outskirts of Vienna or to expand the capacity of its buildings located downtown; the rector's office used TUWEL's “online resources" to present different concepts, invited staff members and students to discuss pros and cons in TUWEL's forums and deployed Moodle's “feedback" module to survey university members' opinions and preferences;

- so far, there is no other centrally maintained tool for content management and for computer supported co-operative work at the university; various commissions and planning committees thus use TUWEL's upload and download features (online resources and forum entries with attachments) to exchange and co-operatively work on documents;

- the medical service department organises appointments with staff members for health checks and specific programmes, e.g. vaccination campaigns, courses, and consulting services: staff members are in the role of course participants, the medical staff acts as teachers; during the summer term 2008, more than 600 appointments have been scheduled, deploying TUWEL's advanced scheduling; 
- deploying Moodle's “feedback" module, the teachers' and researchers' association ran a survey to investigate on job satisfaction, making use of TUWEL's possibility to guarantee that only staff members were able to fill out the form (and only once per person) and that the replies were completely confidential;

- physics teachers co-ordinate contents and learning material of their courses: they use Moodle's "database" module to collect and retrieve data on the relationship between courses, teachers and learning material and to organise for peer reviewing and co-ordinating their teaching material.

We originally expected the departments with the largest number of students to be the ones offering the courses with the largest number of students - but this is not the case. Some non-curricular activities which are implemented in the TUWEL LMS as courses have well over 1,000 registered participants - they are thus larger than all the "regular" courses offered to students (see Fig. 3): The largest (by number of participants) currently offered course is the TUWEL Tutorial introducing teachers to the use of the LMS with 1,362 participants, followed by the "Medical Services" course with 1,214 participants. The largest course in TUWEL so far has been the "Location Debate" in 2006 with 2,925 participants who generated 13,500 "action log entries" for this specific course on the most intensive single day.

Especially the "Location Debate" (which started shortly after TUWEL had been launched) involved many of the university's staff members, and it thus provided more than 1,000 teachers with a positive first contact to the LMS; within only a few days, the number of TUWEL users increased by approximately 1,500, providing the E-Learning Centre with a "jump start" for many of the university's established teachers.

In 2006 and 2007, the E-Learning Centre of Vienna University of Technology provided essential e-teaching training for two persons of (nearly) every department

\begin{tabular}{|r|l|l|r|}
\hline & lourse & curriculum & participants \\
\hline 1 & Location Debate (Rector's Office) & non-curricula & 2,925 \\
\hline 2 & TUWEL Tutorials (E-Learning Centre) & non-curricula & 1,362 \\
\hline 3 & Medical Service Department & non-curricula & 1,214 \\
\hline 4 & Software Engineering and Project Management & Informatics & 778 \\
\hline 5 & Beginning Students' Information and Orientation & Architecture & 772 \\
\hline 6 & Algorithms and Data Structures & Informatics & 749 \\
\hline 7 & Building Theory & Architecture & 745 \\
\hline 8 & Mathematics 1 & Informatics & 707 \\
\hline 9 & Social Issues in Computing & Informatics & 669 \\
\hline 10 & Urban Development & Architecture & 574 \\
\hline 11 & Fundamentals of Computer Science & Informatics & 554 \\
\hline 12 & Introduction to Computer Programming & Mechanical & 415 \\
& & Engineering & 406 \\
\hline 13 & Teachers' and Researchers' Association & non-curricula & \\
\hline
\end{tabular}

Fig. 3. Largest TUWEL courses by number of participants 
who further on act as multipliers and provide first-level support for the department's teachers, further increasing LMS user numbers. Since 2007, all new staff members get in touch with TUWEL for the welcome-events "getTUgether".

\section{Outlook}

In January 2008, Vienna University of Technology started the Enterprise Application Integration project TISS (TU Wien Information Systems and Services, [22, 23]) which will replace the old TUWIS System step by step with a common technological architecture and will enable an interactive application management, supporting the addition of new services. Existing systems will be integrated into a homogeneous, consolidated platform. TISS will provide TUWEL which has grown into an important tool for learning and teaching with interfaces for integration.

Features currently offered by TUWIS, TUWEL, and other platforms in parallel will be harmonised further. TUWEL's features will thus become even easier to use, more effective and efficient. This development will increase university teachers' motivation to use the LMS to improve their teaching provisions.

\section{Conclusions}

In order to utilise the full potential of a centrally managed and maintained learning management system for increasing efficiency for teachers and students by leading to a more homogeneous presentation of learning provisions, the E-Learning Centre of Vienna University of Technology promoted the benefits of applying the platform for teaching purposes by integrating the LMS into the university's central administration system, by adapting the LMS to specific needs and demands of its users, and by encouraging the application of the LMS various purposes.

The learning management system which had originally been introduced to support teacher-student communication for learning purposes thus has become a multipurpose tool supporting all kinds of other co-operation and communication activities, due to the benefit of having a well introduced interface. The E-Learning Centre actually encourages this originally not intended use of the learning platform to further promote its application for teaching purposes. Teachers who had not come in touch with efficient and effective use of online communication and co-operation before experience the benefits at first hand. This gets them start thinking about introducing ICT supported processes into their course concepts, consequently creating new courses and increasing the number of courses available, but also dealing with questions of educational quality and increasing the quality of the courses.

\section{References}

1. Fröhlich, J., Krebs, H., Lohninger, H., Untersteiner, F., Gärtner, P.: iChemEdu - the e Learning concept of the Faculty of Technical Chemistry at the Vienna University of Technology. ZIDline 12 (2005), http: / / www . zid.tuwien.ac .at/zidline/zl12 /

2. http://www.ichemlab.at/ (March 6, 2009) 
3. http://modulor.tuwien.ac.at/ (Feburary 27, 2009)

4. Reichl, F., Vierlinger, U.E., Obermüller, E.: Active Learner Support for eLearning in Continuing Engineering Education: Theory and Practice. In: CIEC - Conference for Industry and Education Collaboration, Savannah (2005)

5. Ehlers, U.-D., Goertz, L., Hildebrandt, B., Pawlowski, J.M.: Quality in e learning. Use and dissemination of quality approaches in European e learning. A study by the European Quality Observatory. Office for Official Publications of the European Communities, Luxembourg (2005),

http: / /www2.trainingvillage.gr/etv/publication/download/ panorama/5162_en.pdf (Feburary 27, 2009)

6. Hagner, P.R.: Interesting practices and best systems in faculty engagement and support. National Learning Infrastructure Initiative (NLII) White Paper (2001), http:// www. educause. edu/ir/library/pdf /NLI0017.pdf (Feburary 27, 2009)

7. http://www. delta (Feburary 27, 2009)

8. Csanyi, et al.: (AutorInnenkollektiv des Projekts Delta 3): Delta 3. Ein eStrategie-Projekt der Technischen Universität Wien, Universität für Bodenkultur Wien \& Akademie der bildenden Künste Wien. In: Seiler Schiedt, E., Kälin, S., Sengstag, C. (eds.) E-Learning Alltagstaugliche Innovation?, pp. 97-107, Waxmann, Münster (2006)

9. Fröhlich, J., Herbst, I.R., Reichl, F.: Delta 3 - ein interuniversitäres Projekt zur Entwicklung und Umsetzung von e Learning-/e Teaching-Strategien an den Partnerinstitutionen. ZIDline 13 (2009),

http://www.zid.tuwien.ac.at/zidline/zl13/delta3.html

(Feburary 27, 2005)

10. Henkel, B., Herbst, I., Krameritsch, J.: Delta3. Ein Strategieprojekt der Technischen Universität Wien, Universität für Bodelkultur Wien \& Akademie der bildenden Künste Wien. 11. Europäische Jahrestagung der Gesellschaft für Medien in der Wissenschaft, Zürich (2006)

11. Reichl, F., Csanyi, G.S., Herbst, I.R., Hruska, A., Obermüller, E., Fröhlich, J., Michalek, C.R., Spiegl, A.: Delta 3 - A Strategic E Education Project Creating Added Value from Complementarity. In: Luca, J., Weippl, E. (eds.) Proceedings of ED-MEDIA 2008 World Conference on Educational Multimedia, Hypermedia and Telecommunications, Association for the Advancement of Computing in Education (AACE), Chesapeake, pp. 465-473 (2008) ISBN 1880094657

12. http://strategie.nml.at/ (Feburary 27, 2009)

13. Kleinmann, B., Wannemacher, K.: E-Learning an deutschen Hochschulen. Von der Projektentwicklung zur nachhaltigen Implementierung. HIS Hochschul-Informations-System GmbH (2004)

14. http: / /www . moodle.org (Feburary 27, 2009)

15. Hruska, A., Potocka, K., Reichl, F.: Mit zwei Klicks zum neuen TUWEL-Kurs. ZIDline 18 (2008), http: / /www.zid.tuwien.ac.at/zidline/zl18/tuwel_kurs/ (Feburary 27, 2008)

16. Hruska, A., Potocka, K., Reichl, F.: E-Learning mit TUWEL - Tendenz stark steigend. ZIDline 16 (2007), http: //www.zid.tuwien.ac.at/zidline/z116/tuwel/ (Feburary 27, 2007)

17. Hruska, A., Potocka, K., Reichl, F.: TUWEL - News WS2008 \& Moodle Konferenz, ZIDline 19 (2009), http: / /www. zid.tuwien.ac.at/zidline/zl19/ (March 6, 2009)

18. http://freemind.sourceforge.net/wiki/index.php/Main_Page (Feburary 27, 2009) 
19. Csanyi, G.S., Jerlich, J., Pohl, M., Reichl, F.: Formal and Informal Technology Enhanced Learning for Initial and Continuing Engineering Education. In: IACEE 11th World Conference on Continuing Engineering Education (WCCEE), Atlanta (2008)

20. Csanyi, G.S.: Informal Learning in the Context of Formal Academic Education - Some Factors of Success. In: Szűcs, A.,, T. (eds.) New Learning Curtures - How do we learn? Where do we learn? EDEN Annual Conference 2008 - New Learning Cultures, Lisbon. EDEN - European Distance and E-Learning Network, Budapest (2008)

21. http://www.tuwien.ac.at/wir_ueber_uns/zahlen_und_fakten/daten/ (Feburary 27, 2009)

22. Kleinert, W., Grechenig, T., Költringer, T., Bernhart, M., Knarek, A., Schönbauer, F.: The Making of TISS: Juni 2008. ZIDline 18 (2008), http: / / www.zid.tuwien.ac.at/zidline/z118/ (March 6, 2008)

23. Suppersberger, M., Bachl, S., Staud, P., Knarek, A., Kleinert, W.: TISS - Planen der Straßen und Roden im Dickicht. ZIDline 19 (2009), http://www.zid.tuwien.ac.at/zidline/zl19/ (March 6, 2009) 